cap-shaped end of which the cervix sits, firmly held. (And herej I would claim that there is a decided advantage in being able to dispense with, in many cases, the ponderous prehension forceps generally used for elevating uterine fibroids through the abdominal wound during operation, and

Frg. 2.

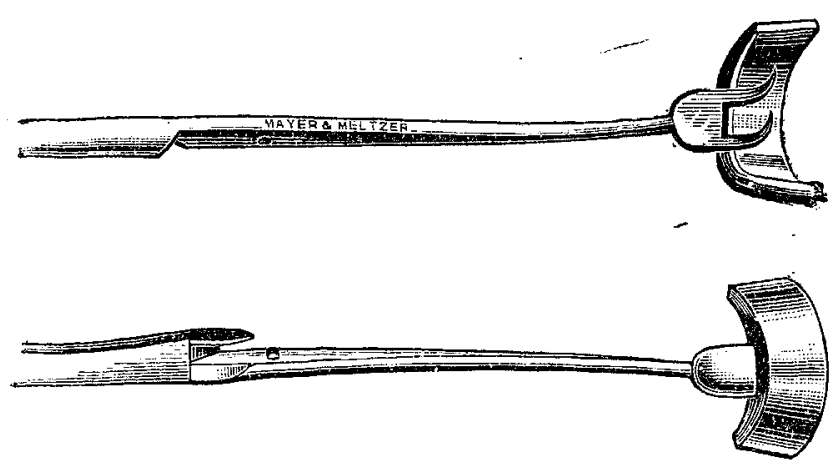

Forceps with blades unlocked.

Bo preventing the annoying hæmorrhage which sometimes takes place from forceps punctures of such tumours.) The broad ligaments were divided between two rows of ligatures, and the usual peritoneal flaps dissected down off the anterior and posterior surfaces of the uterus with blunt scissors and finger. The aterine arteries were now easily picked up on an aneurysm needle and secured outside the reflected peritoneum. The vagina was opened by running a knife around the cervix, within the hollow of the vaginal director, which was still steadied by an assistant and easily felt. Now, instead of suturing the peritoneal flaps as I have done in previous cases, I passed about half a dozen long silk sutures through the edges of the peritoneal flaps and drew them into the vagina, thus completely closing the peritoneal floor. With a Sims speculum the vagina was now well packed with dodoform gauze, firm traction being kept on the flap sutures during the packing. The abdominal wound was closed with deep silkworm gut and superficial horsehair sutures. The vaginal packing was removed on the fourth day after operation, and the sutures on the eighth day. The patient made a perfect recovery and left the hospital on Aug. 27th, 1896.

Melbourne.

\section{A CASE OF HEMICHOREA WITH APHASIA.}

By S. J. ROSS, M.B., CH.B. VICT.,

RESIDENT HOUSE SURGEON, BEDFORD GENERAI INFIRMARY AND FEVER HOSPITAL.

A GIRL, aged fourteen years, at the age of eight years had had an attack of acute rheumatism which left traces behind in the form of well-marked mitral regurgitation. A week kefore being seen she was thrown from a cart, and on the day following the accident her mother noticed that her right arm and leg were constantly in motion and she was restless and never answered questions put to her. Thinking "she was merely shaken" she was put to bed, her parents hoping that by taking rest she would soon be well again. However, as she did not improve I was asked to see her seven days after her fall from the cart. Her condition at this time was as follows. She was in a condition of marked cerebral instability, now laughing and the next minute in tears. Her pupils were dilated. There were marked choreiform movements in the right arm and leg. The tongue was protruded with a jerk and as suddenly withdrawn. The knee-jerk on the right side was exaggerated ; on the left side it was normal. Sensation was normal. There were marked cardiac irregudarity and a mitral systolic murmur conducted to the back, with accentuation of the pulmonary second sound. On being asked questions the patient simply nodded assent or dissent. The movements ceased during sleep.

The treatment adopted was absolute rest, milk only, arsenical solution in increasing doses-as diet at one time she was taking ten minims three times a dayand occasional purgatives. In six weeks she was on full diet and had perfectly regained her power of speech.

Rerarks.-A case such as this points clearly to the cerebral origin of the lesion. The emotion and cessation of movements during sleep, the exaggerated right knee-jerk and aphasia, point clearly to a lesion on the left side of the brain, not permanent, but functional, or at any rate capable of complete resolution. What the exact pathological cbange may be is not known, and, indecd, we must be left in doubt as chorea is a disease so amenable to treatment. Gowers suggests a lowered resistance on the part of the cerebral cells. If this be true it is curious that in cases such as this of true hemichorea this lowered resistance should be limited to the cells on one side of the brain. Others bave suggested a rheumatic inflammation of the cerebral neuroglia - a neurogliosis-these nodules corresponding to the periosteal nodes so frequertly found along bones such as the tibia. Whatever the exact pathological change may be it is certainly curious that arsenic should have absolute control over it-a control which no other drug possesses, except, perhaps, in those cases of convalsive or epileptiform varieties of chorea when a combination of chloral bydrate and bromide of potassium is the most successful treatment, at any rate at first, arsenic frequently being resorted to after the convulsive stage has passed. In offering these remarks of course I do not include that form of nervous disturbance which is often called post-hemiplegic chorea, but which ought rather to be called post-hemiplegic mobile spasm, as suछgested by Gowers.

\section{A CASE OF OBSTRUCTIVE SUPPRESSION OF URINE.}

By F. GRAHAM CROOKSHANK, M D. LOND, LATE HOJSE PHYSICIAN TO THE BROMPTON HOSPITAL.

A LITTLE girl, aged eleven years, was brought to the Brompton Hospital for Consumption and Diseases of the Chest in a state of collapse, the mother stating that almost incessant romiting had occurred for a week; the bowels had been confined during that period. The aspect was suggestively abdominal, and the case appeared to be one of intestinal obstruction. The patient was at once admitted under Dr. Green, who has most kindly allowed me to write this account. The more complete examination then possible failed to detect any abdominal tumour or evidence of peritonitis. The child, although drowsy, was quite conscious; the temperature in the axilla was $96^{\circ} \mathrm{F}$.; the pulse 120 per minute, small and thready; and the respirations were 25 per minute and shallow. On auscultation an apical systolic bruit and moist râles, with friction sounds at the posterior bases of both lungs, were heard. There was no odema. Spasms of the levatores palpebrarum and internal recti occurred every few minutes, bat no other muscular twitchings were noted. The tongue was very foul and the breath was urinous. Further inquiry elicited the fact that three years previously an operation-details of which I have been unable to ascertain-was performed for an abscess of the right kidney. Two years previously there had been a severe illness, lasting several days, the prominent feature of which was agonising pain in the loin. For the last ten days or so there had been much headache, and for a week frequent vomiting. For at least five days prior to admission no urine had been passed, and for several months previously the child had passed urine only at comparatively long intervals (twenty-four hours or more), and then with pain. During the night after admission seven and a half ounces of turbid urine were passed. The urine was acid, of specific gravity 1020, gave a heavy precipitate with picric acid solution, and contained many pus cells, but was without either casts or blood. No more urine was passed during life, and after death the bladder was found to be empty. Vomiting occurred four or five times during the following day, and the spasms of the ocular muscles happened as frequently as before. The pupils were equal and slightly dilated. The child rallied slightly on the whole; the pulse improved, and the rectal temperature rose to $98^{\circ}$, and subsequently to $100^{\circ}$. Towards night the respirations, which had been tranquil, became bissing in cbaracter, and the rate rose to 30 or 35 per minute. The drowsiness increased at the same time. By the early morning these symptoms had passed off, but only to recur with greater severity for an hour or two before death, which took place rather suddenly 
forty-eight hours after admission. Vomiting had taken place about a dozen times in the two days. The child was conscious, and answered questions two hours before death. The only symptom that developed under observation was the hissing character of the respirations.

At the necropsy, which was made by Dr. Habershon, there was found general acute plenrisy, with a deposit of thick yellow lymph over the lower lobe of each lung. The heart weighed four and three-quarter ounces, and the wall of the left ventricle was thickened without any obvious valvular lesion. In the place of the right kidney there was found a mass of fat and fibrous tissue which on section displayed a smooth cavity three inches in length, connected with which were one or two much smaller cavities. These cavities, which obviously represented the pelvis and calices of the kidney, held a few drachms of brownish fluid. A few islets of renal tissue were found scattered in the fat and fibrous tissue. The right ureter (four and $a$ half inches in length) was moderately dilated, and its opening into what had been the pelvis of the kidney was completely blocked. The wall of the bladder was threequarters of an inch in thickness, and the whole organ was hypertrophied without any obvious dilatation. The mucous membrane of the bladder was deeply congested and much pigmented. The left kidney was enlarged, four inches in length, and the pelvis and calices were much dilated. The pyramids were flattened to a thin layer, and the cortex, which was not congested, was slightly fatty and about three-eighths of an inch in thickness. The capsule was not unduly adherent. The first two inches of the left ureter below the pelvis of the kidney were dilated, admitting the little finger with ease. The pelvis and calices of the kidney and this portion of the ureter were distended with clear, urinous fluid. At two inches from its point of origin the ureter was narrowed and the mucous membrane for half an inch vertically was much puckered as if by cicatrisation. A horizontal fold of mucous membrane bere formed a valvalar, but complete, obstruction which could only have been overcome by dilatation of the narrowed portion of the ureter. Below the point of complete obstruction the ureter was again dilated and tortuous, its total length being six and $a$ half inches. The ureter below the obstruction contained no fluid. Probably when the pressure of urine accumulated above the valve reached a certain degree the narrowed portion of the ureter yielded, allowing urine to escape through the valve. The fatal issue must have been due to the fact that finally the obstruction could not be thus overcome, and the pressure of urine accumulated above it had reached the point at which (according to the general view of the pathology of suppression in these cases) further secretion of urine was no longer possible.

The readiest explanation of the anatomical facts seemed to be that the stenosis and puckering were the result of a cicatrix following injury to the ureteric wall from the passage of a calculus, presumably at the time of the illness two years previously. To the obstruction, which must necessarily have been intermittent only until the last week of life, was due the dilatation of the kidney and first part of the ureter. The dilatation of the lower part of the left ureter may have been due to the obstruction afforded by the hypertrophied wall of the bladder. There was no anatomical evidence that regurgitation of urine from the bladder into the ureter had occurred. I have been unable to ascertain whether or no the "abscess" of the right kidney was due to stone. Probably it was. The hypertrophy of the bladder may have resulted (as in diabetes) from the increased quantities of urine it had been called on to discharge from time to time; but the chronic cystitis suggested a more likely cause-namely, that a stone had been retained in the bladder, setting up intermittent obstruction at the neck. The parents could give no information on this as on several other points, beyond stating that the urine had frequently smelt foul and that its passage had given rise to pain.

Although the interpretation of the case in several respects is uncertain, there can, I think, be very little doubt that death was due to obstructive suppression of urine. Clinically, there were two points of difference from the description usually given of such cases-(1) it was the urinous smell that first suggested the correct diagnosis ; and (2) the vomiting was so severe as to suggest intestinal obstruction. In another case that I have seen (in which simultaneons plugging of the ureters by calculi had occurred), vomiting was so grave a symptom as to lead to the diagnosis of intestinal obstruction. Sir William Roberts states that an urinous smell is hardly ever, and persistent vomiting seldom a symptom of obstructive suppression of urine. It is not easy to see why the symptoms of this form of suppression of urine should differ so widely from those of non-obstructive suppression, or why life should be, in the one group of cases, prolonged for such relatively long periods after secretion of urine has ceased without coma supervening. It is generally recognised now that the kidney has other than purely excretory functions, and it is perhaps possible that in obstructive suppression it is the excretory function only or chiefly that is in abeyance, while in non-obstructive suppression all renal functions are suspended. There is experimental evidence which goes some way towards proving that urine ceases to be excreted when the pressure of urine in the pelvis counterpoises the pressure in the renal arterioles. If this be the mechanism of suppression in the obstructive cases, it is quite possible that under such conditions the kidney cells might continue their metabolic (internal secretory) functions. But when such organic disturbance of the renal cells occurs as must be the case in acute nephritis leading to suppression of urine, it is hard to see how any renal functions whatever can be efficiently performed. If this view be in any degree valid we have perhaps some explanation of the difference in symptoms between the two classes of cases of suppression of urine.

Leysfield road, $\mathbf{W}$.

\section{INFLUENZA.}

BY GEOkGE GRESSWELL, M.A. OXFORD AND CAPE OF GooD HOPE, L.R.C.P., L.R.C.S.EDIN., L.F.P.S.GLASG.

THE recent extensive acquaintance with epidemics of this disease in a virulent form, not only in this country, butthroughout the world, is perhaps one of the most instructive and important experiences of the last few years. True it is that, looked at from one aspect, influenza may be classed as a minor scourge. It is well that this is $\mathrm{so}_{\text {, because }}$ science seems as yet almost completely powerless in arresting its spread. As a rule, when properly managed and skilfully treated from the outset, patients do not succumb. Unless dangerous complications are present at first or arise in the course of the complaint the percentage of deaths is only small. Nevertheless, as is well known, very large numbers of people have been affected and rendered incapable. Not only is it the case that whole communities are liable to be stricken down, but it is also a fact that the victims are prostrated with marked nervous, febrile, and catarrhal symptoms, and are afterwards liable to be attacked with distressing and debilitating sequelæ.

One of the most important points is that symptoms pointing to implication of the nervous system are produced, although it has been in past times held that influenza is essentially manifested by a specific kind of inflammation of: the respiratory and alimentary tracts almost exclusively, affecting sometimes in chief part either the one or the other of these, or at other times both either coincidently or consecu. tively. Now we know from repeated practical experience that we must include the nervous system as liable to beattacked quite as readily as either the respiratory or the digestive system. In fact, we must really look upon it as a general infection of the whole system, the blood no doubt being the medium of the distribution of the poison to all parts. However, it often appears to be the case tbat the one or the other of these two systems may be the primary seat of: manifestation. In reality, then, we are considering a specific fever with well.known symptoms, now practically very familiar. As for the temperature, it may be high, and as a rule in all severe cases the mental collapse is so extreme that to the sufferer it may well seem that even death would be preferable to such misery as is experienced. Yet, although not only its origin from infection, but also its. pathology, are extremely simple, the disease may well be termed a protean malady, since so many degrees of severity and so many apparently distinct forms does it assume. It is not, however, difficalt to understand why this malady should affect in divers ways different people and the same person under dissimilar conditions. As a matter of fact, all diseases are liable to variations of type, as is well known; but this is more strikingly shown in the case of influenza, partly, perhaps, on account of its very wide and almost 